\title{
PENGARUH BUNAKEN BRAND, PROMOSI DAN KUALITAS PELAYANAN TERHADAP KEPUASAN TURIS DOMESTIK DAN ASING DI PROVINSI SULAWESI UTARA
}

\author{
Soehardi'; Dino Gobel²; Bambang Sujatmiko3; Mohammad Syofiansur4 \\ Fakultas Ekonomi Universitas Bhayangkara Jakarta Raya ${ }^{1}$ \\ Sekolah Tinggi Filsafat Seminari Pineleng Manado ${ }^{2}$ \\ College of Business Administration, University of Southeastern Philippines ${ }^{3}$ \\ Master in Business Administration, Ateneo de Davao University ${ }^{4}$ \\ soehardi@dsn.ubharajaya.ac.id ${ }^{1}$; dino.gobel@gmail.com²; b.sujatmiko@gmail.com³; \\ m.sofyansur@gmail.com4
}

\begin{abstract}
ABSTRAK
Penelitian ini bertujuan untuk mengetahui pengaruh Bunaken brand, promosi dan kualitas pelayanan terhadap kepuasan turis domestik dan asing di Provinsi Sulawesi Utara. Metode penelitian yang digunakan adalah metode penelitian kualitatif dengan analisis Standardized Loading Factor, Construct Reliability, Average Variance Extract (AVE) dan Uji Model Struktural T Statistics and $P$ Values menggunakan software Partial Least Square atau PLS. Populasi dalam penelitian ini adalah seluruh turis domestik dan asing yang berkunjung ke Provinsi Sulawesi Utara dengan menggunakan purposive sampling diperoleh sample berjumlah 99. Hipotesis pertama tidak ada pengaruh kualitas pelayanan terhadap Bunaken brand. Semakin menurun atau meningkatknya indikator kualitas pelayanan pemandu wisata, fasilitas transportasi, infrastruktur, akomodasi dan kerahmatamahan, maka tidak mempengaruhi Bunaken brand bagi turis domestik dan asing. Hipotesis kedua ada pengaruh kualitas pelayanan terhadap kepuasan turis. Semakin mendominasi indikator kualitas pelayanan pemandu wisata dan fasilitas transportasi, maka turis domestik dan asing semakin merasa puas. Hipotesis ketiga ada pengaruh kualitas pelayanan terhadap promosi. Semakin tinggi kualitas pelayanan pemandu wisata, fasilitas transportasi, infrastruktur, akomodasi dan kerahmatamahan, maka semakin baik promosi Taman Nasional Bunaken kepada turis domestik dan asing. Hipotesis keempat ada pengaruh promosi terhadap Bunaken brand. Semakin meningkat indikator promosi kompetitif, loyalitas, even promosi, informasi pariwisata, maka semakin dikenal citra merek Bunaken oleh turis domestik dan asing. Hipotesis kelima ada pengaruh promosi terhadap kepuasan turis. Semakin meningkat indikator promosi kompetitif, loyalitas, even promosi dan informasi pariwisata, maka semakin semakin merasa puas turis domestik dan asing berkunjung ke TN Bunaken. Hipotesis keenam ada pengaruh Bunaken brand terhadap kepuasan turis. Semakin meningkat indikator brand image, brand experience, brand identity, brand loyalty and brand value, maka semakin puas turis domestik dan asing berkunjung ke TN Bunaken.
\end{abstract}

Kata kunci: Bunaken brand, promosi, kualitas pelayanan dan kepuasan turis domestik dan asing 


\title{
THE EFFECT OF BUNAKEN BRAND, PROMOTION AND SERVICE QUALITY TO THE SATISFACTION OF DOMESTIC AND FOREIGN TOURISTS IN NORTH SULAWESI PROVINCE
}

\begin{abstract}
This study aims to determine the effect of Bunaken brand, promotion and service quality on the satisfaction of domestic and foreign tourists in North Sulawesi Province. The research method used is a qualitative research method with the analysis of Standardized Loading Factor, Construct Reliability, Average Variance Extract (AVE) and Structural Model Test T Statistics and P Values using Partial Least Square or PLS software. The population in this study were all domestic and foreign tourists visiting North Sulawesi Province using purposive sampling obtained a sample of 99. The first hypothesis was that there was no influence of service quality on the Bunaken brand. The declining or increasing indicators of the quality of tour guide services, transportation facilities, infrastructure, accommodation and hospitality, will not affect the Bunaken brand for domestic and foreign tourists. The second hypothesis is the effect of service quality on tourist satisfaction. The more dominating indicators of the quality of tour guide services and transportation facilities, the more satisfied domestic and foreign tourists are. The third hypothesis is the effect of service quality on promotion. The higher the quality of tour guide services, transportation facilities, infrastructure, accommodation and hospitality, the better the promotion of the Bunaken National Park to domestic and foreign tourists. The fourth hypothesis is the influence of promotion on the Bunaken brand. Increasingly competitive indicators of promotion, loyalty, promotional events, tourism information, Bunaken brand image is increasingly recognized by domestic and foreign tourists. The fifth hypothesis is the influence of promotion on tourist satisfaction. Increasingly competitive promotion indicators, loyalty, promotional events and tourism information, the more satisfied domestic and foreign tourists visiting Bunaken National Park. The sixth hypothesis is the influence of the Bunaken brand on tourist satisfaction. The more indicators of brand image, brand experience, brand identity, brand loyalty and brand value, the more satisfied domestic and foreign tourists visit Bunaken National Park.
\end{abstract}

Keywords: Bunaken brand, promotion, service quality and satisfaction of domestic and foreign tourists

Diterima: 16 Maret 2020; Direvisi: 31 Maret 2020; Diterbitkan: 30 April 2020

\section{PENDAHULUAN}

Indonesia adalah negara kepulauan terbesar di dunia dengan memiliki kekayaan sumber daya alam 16.056 pulau-pulau dan 287 pulau pulau di Provinsi Sulawesi Utara. Lokasi yang sangat strategis menjadikan Provinsi Sulawesi Utara sebagai pintu gerbang Asia dan
Pacifik karena berbatasan dengan negara Filipina dan Samudra Pacifik. Rute penerbangan charter flight and regular flight dari luar negeri ke Sam Ratulangi International Airport mengalami pasang dan surut sejak tahun 1995 sampai dengan 2016 disebabkan rendahnya load factor, minimnya penumpang pesawat, belum dikenal Provinsi Sulwesi Utara 
sebagai daerah tujuan wisata dunia dan kurangnya kegiatan promosi pemasaran bisnis pariwisata. Daya tarik wisatawan domestik dan asing berkunjung ke Provinsi Sulawesi Utara antara lain keindahan alam Taman Nasional Bunaken, Selat Lembeh, Gunung Api Bawah Laut, Danao Tandano, dan lain-lain.

Beberapa kelemahan untuk meningkatkan turis asing dan domestik berkunjung ke Provinsi Sulawesi Utara antara lain: minimnya konektivitas rute penerbangan dari luar negeri menuju Sam Ratulangi International Airport; belum adanya rute pelintasan pelayaran kapal pesiar luar negeri yang membawa penumpang asing menuju Bitung International Seaport; belum banyaknya turis asing mengetahui kebijakan visa on arrival Sam Ratulangi International Airport; kurangnya kekompakan North Sulawesi Tourism Stakeholders dalam mempromosikan international and national events; dan belum tersosialisasinya dengan baik North Sulawesi tourism destination kepada KBRI, KJRI dan Indonesia Diaspora Network di luar negeri, belum maksimalnya kerja sama dengan foreign embassy and foreign travel and tours.

Pemerintah Sulawesi Utara belum maksimal melaksanakan sosialisasi strategi pemasaran bisnis pariwisata kepada masyarakat dalam negeri dan luar negeri melalui pemanfaatn Information and Communication Technology (UICT) seperti digital marketing di online business dan media sosial tahun 1995 sampai 2016. Kurangnya pemandu wisata yang memiliki kemampuan berbahasa Inggris dan Mandarin karena kurangnya tenaga ahli instruktur dan pelatihan berbahasa asing dan banyak diketemukan penunjuk jalan di jalan raya dan tempat wisata masih menggunakan bahasa Indonesia belum memakai bahasa Inggris dan Mandarin serta pelayanan yang belum maksimal di tempat tujuan wisata.

Wisatawan asing asal Tiongkok menggunakan transportasi udara charter flight Lion Air and Citilink yang melayani rute penerbangan dari Shanghai, Guangzhou, Nanjing, Changsha, Wuhan, Tianjin, Zhengzhou, Nanning dan Xian menuju Sam
Ratulangi International Airport. Silk Air dengan rute Singapura ke Sam Ratulangi International Airport membawa penumpang turis asing asal WN Singapura, Belanda dan Amerika Serikat. Sedangkan turis asing asal WN Filipina dapat memanfaatkan Garuda Indonesia Airways yang melayani rute Davao International Airport ke Sam Ratulangi International Airport dengan waktu tempuh kurang dari 1 jam

Pembuatan Icon "Taman Nasional Bunaken" dan Selat Lembeh dimasukan sebagai daerah tujuan wisata Indonesia dan juga sebagai tempat "foreign drama films," serta visa on arrival diberlakukan di Sam Ratulangi International Airport menjadi daya tarik tersendiri bagi wisatawan domestik dan asing berkunjung ke Provinsi Sulwesi Utara. Tanggal 4 Juli 2016 merupakan hari bersejarah ditandai banyaknya wisatawan asing asal Tiongkok berkunjung ke Provinsi Sulwesi Utara atau dapat dikatakan Sang Pembuka Gerbang Asia Pacifik Gubernur Olly Dodokambey telah membuktikan Sulawesi Utara sebagai daerah tujuan wisata Indonesia dan dunia. Kedatangan wisatawan asing asal Tiongkok, Hongkong, Singapura, Taiwan, Korea, Jepang, Belanda, Jerman dan Amerika Serikat untuk mengetahui lebih mendalam wisata bahari di Provinsi Sulwesi Utara.

\section{LANDASAN TEORI}

\section{Kebijakan Pemerintah Pusat}

(Gobel, 2018) mengatakan bahwa strategi Gubernur Provinsi Sulawesi Utara, Olly Dodokambey dalam melakukan beberapa kali pertemuan langsung dengan Presiden Joko Widodo dan Wakil Presiden Jusuf Kalla mendapatkan hasil yang signifikan dengan dikeluarkannya beberapa kebijakan antara lain: Visa on arrival di Sam Ratulangi Internasional Airport. Kebijakan VoA di Sam Ratulangi Internasional Airport mulai berlaku sejak tahun 2016. Kebijakan ini terbukti sangat mendukung peningkatan kunjungan turis asing asal Tiongkok, Filipina dan Belanda berkunjung ke Indonesia. 
(Gobel, 2018) menyebutkan salah satu pilar “Olly Dondokambey Tourism Strategies (ODTS)” adalah penguatan sinerjitas pemerintah beserta tourism stakeholders melalui satuan tugas pariwisata atau yang lebih dikenal dengan nama tourism promotion task force. ODTS ini menghasilkan banyak ide dan kreasi aktif buyer meet seller di luar negeri yang diselenggarakan oleh Asosiasi Tour and Travel Indonesia (ASITA), Perhimpunan Hotel dan Restoran Indonesia (PHRI), Asosiasi Pelaku Pariwisata Indonesia (ASPPI), Himpunan Pramuwisata Indonesia (HPI) dan Indonesian Hotel General Manager Association (IHGMA). ODTS yang melibatkan para walikota dan bupati bersama dengan asosiasi dan perhimpunan pariwisata ini berdampak positif terhadap kedatangan turis domestik dan asing ke Sulawesi Utara. Salah satu pilar komitmen ODTS ini adalah foreign and domestic investment commitment untuk memicu kepercayaan atau trust, dari trust ini lahirlah antusias tourism stakeholders untuk menyatu dengan gerakan pemerintah dalam upaya mendukung pariwisata.

Pemerintah Indonesia mengeluarkan beberapa kebijakan dalam mendukung pemasaran bisnis pariwisata Propvinsi Sulwesi Utara dengan memberlakukannya ijin operasional Sam Ratulangi Internasional Airport (SRIA) selama 24 jam, maka jadwal keberangkatan dan kedatangan dari luar negeri ke SRIA dapat dilaksanakan kapanpun sehingga dapat meningkatkan kunjungan wisatawan asing ke Sulawesi Utara.

\section{Bunaken Brand dan Promosi Pemasaran}

Pemerintah Provinsi Sulawesi Utara mengkoordinasikan pelayanan satu atap Kantor Pariwisata dengan Custom, Immigration, Quarantine and Security (CIQS), Angkasa Pura Polri dan TNI, ASITA, PHRI, ASPPI, HPI dan IHGMA. Tugasnya membuat kebijakan bisnis pariwisata tentang strategi membuat keyakinan turis asing sangat memuaskan dan berkeinginan kembali lagi ke Sulawesi Utara. Selain itu, Kantor Dinas Pariwisata dijadikan sebagai Kantor Promosi dan Pemasaran.
Pemerintah Sulawesi Utara juga meningkatkan kualitas sumber daya manusia dalam mendukung strategi pemasaran bisnis pariwisata dengan cara mengirim 50 mahasiswa kuliah di beberapa Universitas di Republik Rakyat Tiongkok. 100 polisi dari Polda Sulut belajar bahasa Mandarin untuk menjadikan sebagai "Tourism Police" yang didanai oleh Pemerintah Provinsi Sulawesi Utara.

Likupang sebagai Zona Ekonomi Khusus Pariwisata Provinsi Sulawesi Utara yang posisinya sangat strategis berada antara Bunaken National Park sebagai tourism icon and Lembah Strait. International and national events antara lain: Bunaken National Park and Lembah Strait Festivals, Manado Fiesta Festival, Christmas Festival and Ramadhan Festival, Tournament of Flowers di Tomohon Minahasa, Gulf of Tomini Festival di Bolaang Mongondow Selatan, Batu Pinagut Festival di Bolaang Mongondow Utara, Tulude Ceremony di Kabupaten Sangihe dan Sitaro dan Manee Festival di Talaud.

Menurut (Goeldner \& $\mathrm{R}, \quad 2009$ ) pariwisata adalah orang yang berpartisipasi dalam konvensi, konferensi bisnis, atau jenis bisnis atau profesional lainnya kegiatan, serta mereka yang mengambil studi wisata di bawah panduan ahli atau melakukan semacam ilmiah penelitian atau studi. Menurut (Stefan, 2013), pariwisata adalah jumlah dari fenomena dan hubungan yang timbul dari interaksi antara turis, pemasok bisnis, pemerintah tuan rumah, masyarakat tuan rumah, asal pemerintah, universitas, perguruan tinggi dan organisasi non-pemerintah, dalam proses menarik, mengangkut, menampung dan mengelola wisatawan ini dan pengunjung lain.

Menurut (Aziri \& Nedelea, 2013), strategi pemasaran bisnis pariwisata adalah strategi produk menetapkan serangkaian tujuan khusus untuk daerah ini sebagai: penilaian unggul dari potensi wisata, meningkatkan wisatawan domestik dan asing, mempromsikan produk wisata baru, memperoleh daya saing produk wisata dan memaksimalisasi kualitas dan harga produk dan jasa bisnis pariwisata. 
Strategi pemasaran produk pariwisata terdiri dari: peningkatan beberapa fasilitas layanan tambahan seperti pusat kebugaran, modifikasi struktur produk misalnya peningkatan klasifikasi produk dan jasa hotel. Pengembangan diversifikasi produk dan jasa baru seperti modifikasi transportasi, akomodasi, pasokan publik, atau layanan diiklankan yang ditawarkan kepada konsumen atau tur wisata. Strategi diversifikasi menyiratkan pengembangan simultan dari produk wisata baru misalnya operator tur memvariasikan campuran produknya menawarkan juga wisata dengan karakter budaya atau liburan perawatan di resort.

Menurut (Aziri \& Nedelea, 2013) strategi pemasaran bisnis pariwisata adalah daya tarik produk wisata low season dapat ditingkatkan dengan menawarkan beberapa variasi opsi tempat tujuan misalnya program berburu atau memancing, berkuda, perjalanan yang berbeda, program rakyat, hiking, dan lain-lain. Strategi harga dapat dilihat harga tinggi misalnya strategi harga kontrak (kontraktual, inklusif, "semua inklusif"), strategi tarif berbeda untuk industri pariwisata, strategi diskon dan bonus (diadopsi oleh perusahaan pariwisata yang menyesuaikan harga dasar produk untuk menarik wisatawan domestic dan asing tertentu, yaitu: klien yang meminta layanan dengan volume tinggi, klien yang menerima liburan selama musim sepi). Strategi distribusi yang diadopsi oleh operator pariwisata mempertimbangkan: penjualan layanan turis layanan pergi ke beberapa agen lainnya, segmen konsumen yang sama, penjualan produk yang sama melalui berbeda saluran distribusi ke berbagai segmen konsumen publik, penjualan lebih banyak produk melalui berbagai saluran distribusi ke satu atau lebih segmen konsumen di pasar.

(Koththagoda, 2017) mengatakan bahwa arti penting merek, kinerja merek, citra merek, perasaan merek, penilaian merek, resonansi merek adalah faktor yang berpengaruh terhadap persepsi merek yang meningkatkan kepuasan pelanggan terhadap industri pariwisata di Sri Langka. (Noori \& Nisa, 2019) mengatakan bahwa implikasi disajikan untuk sektor pariwisata fokus pada penerapan branding untuk tujuan wisata yang lebih baik dan untuk memenuhi kepuasan pelanggan.

(Singh \& Mehraj, 2018) mengatakan pengalaman merek mempengaruhi kepuasan wisatawan yang pada gilirannya mempromosikan tujuan melalui mulut ke mulut dan ulangi bepergian ke tujuan. Konsep pengalaman merek tujuan membentuk dasar untuk menilai kemampuan tujuan wisata lokal untuk mengeksploitasi pengalaman ini sebagai sarana untuk memperkaya kinerjanya. Penempatan pengalaman merek tujuan, termasuk pengalaman sensorik, afektif, perilaku, dan intelektual, memainkan peran penting dalam tujuan branding dan pengembangan tujuan. (Castro et al., 2017) dengan judul Tourism Marketing: Measuring Tourist Satisfaction di Journal of Service Science and Management mengatakan bahwa indikator promosi terdiri dari: promosi kompetitif, loyalitas, diskon dan event promosi.

\section{Kualitas Pelayanan Dan Kepuasan Turis}

Menurut (Al-Ababneh, 2013), kualitas pelayanan berpengaruh langsung terhadap kepuasan turis seperti aksesibiliti, fasilitas tujuan wisata dan daya tarik tujuan wisata. Aksesibiliti termasuk biaya, kecepatan dan kemudahan transportasi umum di daerah tujuan wisata. Akomodasi restoran, café, dan jasa transportasi dapat dikategorikan sebagai fasilitas tujuan wisata, termasuk juga toko souvenir dan retails, jasa informasi dan polisi pariwisata. Daya tarik tujuan dan lingkungan wisata dapat memotivasi turis berkunjung ke tempat obyek wisata seperti arsitektur sejarah dan modern, budaya, seni dan lain-lain.

Menurut (Gupta \& Srivastava, 2011) proses hirarki analisis untuk mengakses kepuasan pelanggan tentang kualitas pelayanan hotel (pelayanan ruang resepsi pertemuan, pelayanan ruang kamar dan restoran. Menurut (Ebrahimpour \& Haghkhah, 2010) mengindikasikan dimensi seperti aksesibiliti akomodasi, tempat tujuan wisata dan 
komponen lainnya memiliki kontribusi langsung pada kepuasan turis, dan pengembangan industry pariwisata.

Menurut (Corte et al., 2014) bahwa 14 ukuran kepuasan turis dengan cara kemudahaan akses melalui perbedaan moda transportasi, kualitas jalan dan rambu-rambu jalan, aneka macam dan klualitas restoran, entertainment, harga dan nilai, aksesibiliti informasi, transportasi lokal, keamanan yang dirasakan, infrastruktur yang baik, kebersihan kota, keramah-tamahan masyarakat, event dan kegiatan budaya organisasi.

\section{Kerangka Pemikiran}

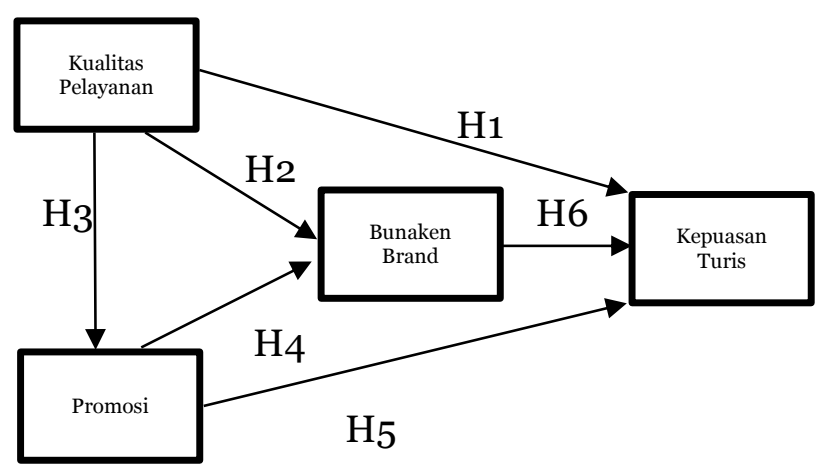

Gambar 1. Kerangka Penelitian

\section{Hipotesis}

H1: Ada pengaruh kualitas pelayanan terhadap kepuasan turis domestik dan asing di Provinsi Sulawesi Utara

H2: Ada pengaruh kualitas pelayanan terhadap Bunaken Brand di Provinsi Sulawesi Utara

H3: Ada pengaruh kualitas pelayanan terhadap promosi di Provinsi Sulawesi Utara

H4: Ada pengaruh promosi terhadap Bunaken brand di Provinsi Sulawesi Utara;

$\mathrm{H}_{5}$ : Ada pengaruh promosi terhadap kepuasan turis domestik dan asing di Provinsi Sulawesi Utara;

H6: Ada pengaruh Bunaken brand terhadap kepuasan turis domestik dan asing di Provinsi Sulawesi Utara;

\section{METODE PENELITIAN}

Metode penelitian yang digunakan adalah metode penelitian kualitatif dengan analisis Standardized Loading Factor (SLR), Construct Reliability (CR), Average Variance Extract (AVE) dan Uji Model Struktural $T$ Statistics and $P$ Values menggunakan software Partial Least Square atau PLS. Populasi adalah seluruh turis domestic dan asing di Provinsi Sulawesi Utara dan purposive sampling dipilih untuk mengambil sampel menjadi berjumlah 99 orang. Data primer diperloleh melalui kegiatan wawancara dengan kuesioner yang berdasarkan variabel bebas dan terikat, dimensi dan indikator serta observasi lapangan dan dokumentasi. Informasi dan data sekunder bersumber dari Staf Khusus Gubernur Sulawesi Utara, Dinas Pariwisata Provinsi Sulawesi Utara, Kantor Imigrasi Kelas I Manado, Kantor Imigrasi kelas II Bitung, Association of the Indonesian Tours and TravelAgencies.

\section{HASIL DAN PEMBAHASAN}

Tabel 1. Wisatawan Domestik dan Asing

\begin{tabular}{|c|c|c|}
\hline \multicolumn{3}{|c|}{2015 - 2019} \\
\hline 2015 & $\begin{array}{c}\text { Wisatawan } \\
\text { Domestik }\end{array}$ & Persentase \\
\hline 2016 & 1.070 .681 & $66,47 \%$ \\
\hline 2017 & 1.600 .000 & $12,50 \%$ \\
\hline 2018 & $\begin{array}{c}2.000 .000 \\
2000\end{array}$ \\
\hline 2019 & $\begin{array}{c}2.400 .000 \\
\text { (target) }\end{array}$ & $16,66 \%$ (target) \\
\hline & Rata-Rata & $28,90 \%$ \\
\hline
\end{tabular}

Sumber Dinas Pariwisata Provisni Sulwesi Utara, 2019

Tabel 2. Wisatawan Asing 2015 - 2019

\begin{tabular}{|c|c|c|}
\hline Tahun & Wisatawan Asing & Persentase \\
\hline 2015 & 15.000 & \\
\hline
\end{tabular}




\begin{tabular}{|c|c|c|}
\hline 2016 & 48.000 & $68,75 \%$ \\
\hline 2017 & 84.000 & $42,85 \%$ \\
\hline 2018 & 100.000 & $16,00 \%$ \\
\hline 2019 & 150.000 (target) & \\
\hline & Rata-Rata & $42,53 \%$ \\
\hline
\end{tabular}

Sumber Dinas Pariwisata Provinsi Sulawesi Utara, 2019

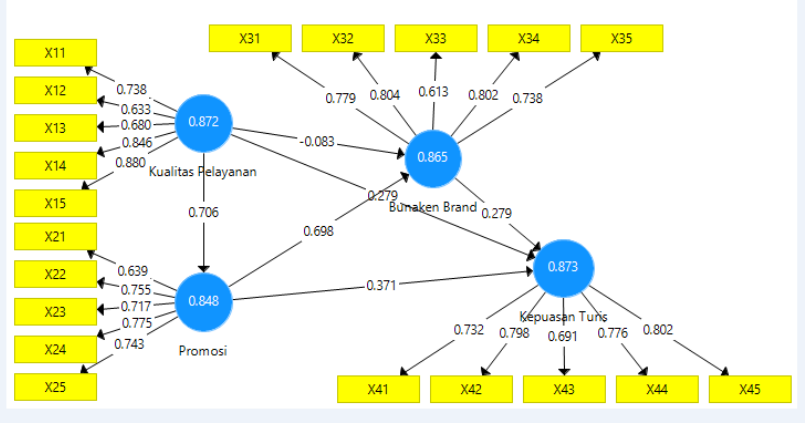

Gambar 2. Composite Reliability

Tabel 3. Kamar Hotel di Sulawesi Utara tahun 2019

Hotel Kelas Bintang|Hotel Kelas Keterangan Melati

\begin{tabular}{|l|l|l|}
\hline 22 hotel & 36 Hotel & 5.112 kamar \\
\hline
\end{tabular}

Sumber Dinas Pariwisata dan BPS Provinsi Sulawesi Utara, 2019

Tabel 4. International Direct Flight to Sam Ratulangi International Airport

\begin{tabular}{|c|c|c|}
\hline Airline & City and Country & Frequency \\
\hline Silk Air & Singapore & 5 times per week \\
\hline Lion Air & Changsa & 3 time per day \\
\hline & Tianjin & Charter Flight \\
\hline & Shenzhen & Charter Flight \\
\hline & Guangzhoe & Charter Flight \\
\hline & Shanghai & Charter Flight \\
\hline & Nanjing & Charter Flight \\
\hline & Wuhan & Charter Flight \\
\hline & Zhengzhou & Charter Flight \\
\hline \multicolumn{2}{|c|}{ Nanning } & Charter Flight \\
\hline $\begin{array}{c}\text { Garuda } \\
\text { Andonesia }\end{array}$ & Davao & Charter Flight \\
\hline
\end{tabular}

Sumber: Kantor Imigrasi Kelas I Manado, 2019

Pada data software Partial Least Square (PLS) dihasilkan uji validitas dan reliabilitas variable laten Bunaken brand, promosi, kualitas pelayanan dan kepuasan turis adalah baik karena Standardized Loading Factor (SLF) memenuhi kriteria $\geq 0,50$ dan reliabilitas baik karena nilai Construct Reliability (CR) > 0.70 serta Average Variance Extract (AVE) > 0.50

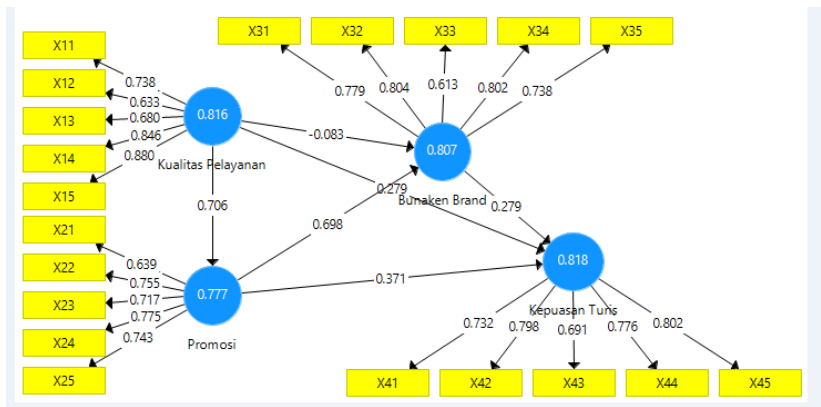

Gambar 2. Cronbach's Alpha

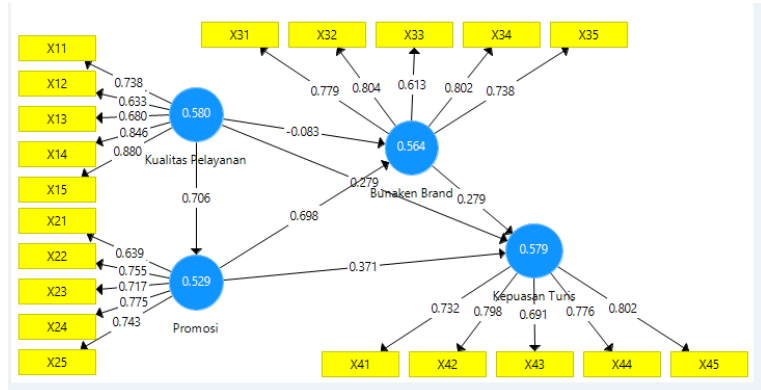

Gambar 3. Average Variance Extract

Berdasarkan uji model structural $t$ values and $P$ values dengan software PLS menunjukkan hasil sebagai berikut: Hipotesis pertama thitung $(0,631) \leq \mathrm{t}$ tabel $(1,99)$ dengan $P$ value hitung $(0,528) \geq 0,05$, dapat diartikan tidak ada pengaruh dan tidak signifikan kualitas pelayanan terhadap Bunaken brand; Hipotesis kedua $\mathrm{t}$ hitung $(2,118) \geq$ dari $\mathrm{t}$ tabel $(1,99)$ dengan $\mathrm{P}$ value hitung $(0,035) \leq 0,05$, dapat diartikan ada pengaruh yang signifikan kualitas pelayanan terhadap kepuasan turis; Hipotesis ketiga $t$ hitung $(10,083) \geq$ dari t tabel $(1,99)$ dengan $\mathrm{P}$ value hitung $(0,00) \leq 0,05$, dapat diartikan ada pengaruh yang signifikan kualitas 
pelayanan terhadap promosi; Hipotesis keempat t hitung $(6,047) \geq$ dari t tabel $(1,99)$ dengan $\mathrm{P}$ value hitung $(0,00) \leq 0,05$, dapat diartikan ada pengaruh yang signifikan promosi terhadap Bunaken brand; Hipotesis kelima t hitung $(3,057) \geq$ dari $t$ tabel $(1,99)$ dengan $\mathrm{P}$ value hitung $(0,002) \leq 0,05$, dapat diartikan ada pengaruh yang signifikan promosi terhadap kepuasan turis; Hipotesis keenam $t$ hitung $(2,263) \geq$ dari $t$ tabel $(1,99)$ dengan $P$ value hitung $(0,024) \leq 0,05$, dapat diartikan ada pengaruh yang signifikan Bunaken brand terhadap kepuasan turis;

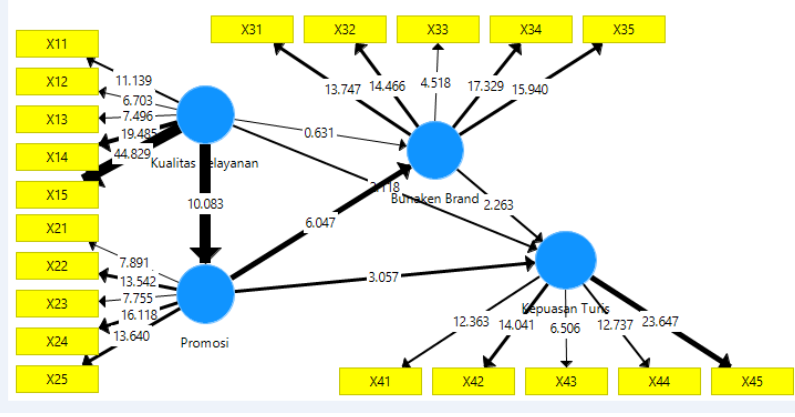

Gambar 4. Uji t

Tabel 8. Uji Model Struktural T Statistics and $P$ Values

\begin{tabular}{|c|c|c|c|c|c|c|}
\hline \multirow[t]{2}{*}{ Mean, STDEV, } & \multirow{2}{*}{$\begin{array}{l}\text { T-Values, P-Va... } \\
\text { Original Sampl... }\end{array}$} & \multicolumn{2}{|c|}{ Confidence Intervals } & \multicolumn{2}{|c|}{ Confidence Intervals Bias C... } & \multirow{2}{*}{$\begin{array}{l}\text { Sample } \\
\text { P Values }\end{array}$} \\
\hline & & Sample Mean (... & Standar & rd Devia... & T Statistics (|0... & \\
\hline Bunaken Brand... & 0.279 & 0.272 & & 0.123 & 2.263 & 0.024 \\
\hline Kualitas Pelaya... & -0.083 & -0.068 & & 0.131 & 0.631 & 0.528 \\
\hline Kualitas Pelaya... & 0.279 & 0.275 & & 0.132 & 2.118 & 0.035 \\
\hline Kualitas Pelaya... & 0.706 & 0.714 & & 0.070 & 10.083 & 0.000 \\
\hline Promosi -> Bu... & 0.698 & 0.703 & & 0.115 & 6.047 & 0.000 \\
\hline Promosi -> Ke... & 0.371 & 0.379 & & 0.121 & 3.057 & 0.002 \\
\hline
\end{tabular}

\section{Pembahasan}

\section{Kualitas Pelayanan terhadap Bunaken Brand}

Hipotesi Ho diterima karena t hitung $(0,631) \leq \mathrm{t}$ tabel $(1,99)$ dengan $\mathrm{P}$ value hitung $(0,528) \geq 0,05$, dapat diartikan tidak ada pengaruh dan tidak signifikan kualitas pelayanan terhadap Bunaken brand. Peneliti menganilisis baik atau buruknya kualitas pelayanan, tidak akan mempengaruhi turis domestic dana sing berkunjung ke Taan Nasional Bunaken. Penelitian ini bertolak belakang dengan penelitian sebelumnya yang dilakukan oleh (Malik et al., 2011) dengan judul Impact of Service Quality on Brand Image : Empirical Evidence from Hotel Industry yang mengatakan ada pengaruh kualitas pelayanan terhadap brand.

\section{Kualitas Pelayanan terhadap Kepuasan Turis}

Hipotesis $\mathrm{H} 1$ diterima karena t hitung $(2,118) \geq$ dari $t$ tabel $(1,99)$ dengan $\mathrm{P}$ value hitung $(0,035) \leq 0,05$, dapat diartikan ada pengaruh yang signifikan kualitas pelayanan terhadap kepuasan turis. Penelitian ini mendukung penelitian sebelumnya yang dilakukan oleh (Review et al., 2013) dengan judul Influence of Customer Satisfaction on Service Quality and Trust yang menyatakan ada pengaruh kualitas pelayanan terhadap kepuasan konsumen pada pariwisata daerah di Malaysia.

Penelitian ini juga mendukung penelitian sebelumnya yang dilakukan oleh (Puri \& Singh, 2018) dengan judul The Role of Service Quality and Customer Satisfaction in Tourism Industry : A Review of Servqual Model. Untuk mengelola kualitas pelayanan dirasakan perlu untuk mencocokkan pelayanan yang diharapkan dan dirasakan satu sama lain sehingga kepuasan wisatawan dapat tercapai. Penelitian ini mendukung penelitian sebelumnya yang dilakukan oleh (Al-Ababneh, 2013) dengan judul Service Quality and Its Impact on Tourist Satisfaction dan (Corte et al., 2014) dengan judul Customer Satisfaction in Tourist Destination; The Case of Tourist Offer in the City of Naples. 


\section{Kualitas Pelayanan terhadap Promosi}

Hipotesis $\mathrm{H} 1$ diterima karena t hitung $(10,083) \geq$ dari t tabel $(1,99)$ dengan $\mathrm{P}$ value hitung $(0,00) \leq 0,05$, dapat diartikan ada pengaruh yang signifikan kualitas pelayanan terhadap promosi. Semakin baik kualitas pelayanan dapat memudahkan Pemerintah Provinsi Sulawesi Utara untuk meningkatkan promosi pariwisata Taman Nasional Bunaken kepada turis domestik dan asing.

\section{Promosi Terhadap Bunaken Brand}

Hipotesis $\mathrm{H} 1$ diterima karena t hitung $(6,047) \geq$ dari $t$ tabel $(1,99)$ dengan $P$ value hitung $(0,00) \leq 0,05$, dapat diartikan ada pengaruh yang signifikan promosi terhadap Bunaken brand; Penelitian ini mendukung penelitian sebelumnya yang dilakukan oleh (Buil et al., 2010) dengan judul The effect of advertising and sales promotions on brand equity yang menyatakan promosi memiliki pengaruh positif pada asosiasi merek. Peneliti menganilisi bahwa Pemerintah Provinsi Sulawesi Utara telah berhasil dengan baik dalam mempromosikan Bunaken brand dan obyek wisata lainnya kepada turis domestik dan asing. Dimensi promosi menurut (Kotler \& Keller, 2016) terdiri dari sales promotion, advertising, sales force, public relation and direct marketing.

\section{Promosi Terhadap Kepuasan Turis}

Hipotesis $\mathrm{H} 1$ diterima karena $\mathrm{t}$ hitung $(3,057) \geq$ dari $t$ tabel $(1,99)$ dengan $P$ value hitung $(0,002) \leq 0,05$, dapat diartikan ada pengaruh yang signifikan promosi terhadap kepuasan turis; Penelitian ini mendukung penelitian sebelumnya yang dilakukan oleh (Khan, 2016) dengan judul Impact of Promotional Mix Elements on Tourist's Satisfaction : A Case Study of Mussoorie. Peneliti menganalisis bahwa Pemerintah Provinsi Sulawesi Utara telah berhasil dengan baik dalam mempromosikan Bunaken brand dan obyek wisata lainnya sehingga turis domestik dan asing merasa puas. Dimensi kepuasan turis menurut (Salleh et al., 2013) dengan judul Tourist Satisfaction in Malaysia terdiri dari beautiful scenery, custom and culture, hospitality of the service providers, the quality of food and the friendliness of the locals.

\section{Bunaken Brand terhadap Kepuasan Turis}

Hipotesis H1 diterima karena t hitung $(2,263) \geq$ dari $t$ tabel $(1,99)$ dengan $P$ value hitung $(0,024) \leq 0,05$, dapat diartikan ada pengaruh yang signifikan Bunaken brand terhadap kepuasan turis. Penelitian ini mendukung penelitian sebelumnya yang dilakukan oleh (Rahayu, 2015) dengan judul The Effect of Promotion, Service Quality, Brand Image on the Satisfaction of the Tourists Visiting the City Palembang and the Implication on Their Loyalty to the Visited Resorts yang menyatakan ada pengaruh brand terhadap kepuasan turis. Dimensi dari Bunaken brand terdiri dari brand image, brand experience, brand identity, brand loyalty and brand value.

\section{KESIMPULAN DAN SARAN}

\section{Kesimpulan}

Kesimpulan dalam penilitian ini adalah sebagai berikut:

1. Hipotesis pertama tidak ada pengaruh kualitas pelayanan terhadap Bunaken brand. Semakin menurun atau meningkatknya indikator kualitas pelayanan pemandu wisata, fasilitas transportasi, infrastruktur, akomodasi dan kerahmatamahan, maka tidak mempengaruhi Bunaken brand bagi turis domestik dan asing;

2. Hipotesis kedua ada pengaruh kualitas pelayanan terhadap kepuasan turis. Semakin 
mendominasi indikator kualitas pelayanan pemandu wisata dan fasilitas transportasi, maka turis domestik dan asing semakin merasa puas;

3. Hipotesis ketiga ada pengaruh kualitas pelayanan terhadap promosi. Semakin tinggi kualitas pelayanan pemandu wisata, fasilitas transportasi, infrastruktur, akomodasi dan kerahmatamahan, maka semakin baik promosi Taman Nasional Bunaken kepada turis domestik dan asing;

4. Hipotesis keempat ada pengaruh promosi terhadap Bunaken brand. Semakin meningkat indikator promosi kompetitif, loyalitas, even promosi, informasi pariwisata, maka semakin dikenal citra merek Bunaken oleh turis domestik dan asing;

5. Hipotesis kelima ada pengaruh promosi terhadap kepuasan turis. Semakin meningkat indikator promosi kompetitif, loyalitas, even promosi, informasi pariwisata, maka semakin semakin merasa puas turis domestik dan asing berkunjung ke TN Bunaken;

6. Hipotesis keenam ada pengaruh Bunaken brand terhadap kepuasan turis. Semakin meningkat indikator brand image, brand experience, brand identity, brand layalkty and brand value, maka semakin puas turis domestik dan asing berkunjung ke TN Bunaken.

\section{Saran}

1. Disarankan kepada pemerintah pusat sebaiknya membentuk Badan Otorita Taman Nasional Bunaken agar pengelolaan dan perawatan menjadi satu atap dalam upaya lebih melestarikan ekosistem flora dan fauna dan lebih meningkatkan kunjungan turis domestik dan asing ke Sulawesi Utara

2. Pemerintah Provinsi Sulawesi Utara bekerja sama dengan international and domestic travel and tours sebaiknya memiliki program kegiatan promosi pemasaran yang komprehensif dan berkelanjutan untuk mendukung Bunaken brand sebagai tourism icon pariwisata unggulan yang memiliki keragaman flora dan fauna beserta ekosistem dalam laut dalam upaya meningkatkan kunjungan turis domestik dan asing;

3. Pemerintah Provinsi Sulawesi Utara sebaiknya memberikan pelatihan yang intensif tentang kualitas pelayanan dan promosi pemasaran (digital marketing) kepada tourism stakeholders dalam upaya lebih meningkatkan kepuasan turis domestik dan asing berkunjung ke Sulawesi Utara;

4. Pemerintah Provinsi Sulawesi Utara bekerja sama dengan Dinas Pendidikan dan Kebudayaan serta Dinas Industri da Perdagangan sebaiknya memiliki program kegiatan mempromosikan Bunaken brand bersamaan dengan education tourism and industrial tourism agar lebih banyak lagi turis domestik dan asing berkunjung ke Sulawesi Utara.

\section{Daftar Pustaka}

Al-Ababneh, M. (2013). Service $\backslash n Q u a l i t y$ and its Impact on Tourist Satisfaction.

Interdisciplinary $\mid$ nJournal of Contemporary Research in Business, 164-177.

Aziri, B., \& Nedelea, A. (2013). Business Strategies in Tourism. Http://Www.Ecoforumjournal.Ro/Index. Php/Eco/Article/View/21/12, 2(1 (2)).

Buil, I., Chernatony, L. de, \& Martínez, E. (2010). The effect of advertising and sales promotions on brand equity. 6th Thought Leaders in Brand Management International Conference, February 201O, 1-13.

Castro, J. C., Quisimalin, M., Pablos, C. de, Gancino, V., \& Jerez, J. (2017). Tourism Marketing: Measuring Tourist Satisfaction. Journal of Service Science and Management, 10(03), 1-29. https://doi.org/10.4236/jssm.2017.10302 3

Corte, V. Della, Sciarelli, M., Cascella, C., \& Gaudio, G. Del. (2014). Customer satisfaction in tourist destination: The case of tourism offer in the city of Naples. 
Journal of Investment and Management, 4(1-1), 39-50.

https://doi.org/10.11648/j.jim.s.20150401 01.16

Ebrahimpour, A., \& Haghkhah, A. (2010). The Role of Service Quality in Development of Tourism Industry. Tourism Journal.

Gobel, D. (2018). Sang Pembuka Gerbang (S. O. E. Kondouw \& G. A. Putro (eds.); Cetakan Pe). PT Gramedia, Jakarta.

Goeldner, \& R, R. (2009). Tourism: Principles, Practices, Philosophies, Eleventh edition. In Tourism: Principles, Practices, Philosophies, Eleventh edition.

Gupta, P., \& Srivastava, R. K. (2011). Analysis of Customer Satisfaction in Hotel Service Quality Using Analytic Hierarchy Process (Ahp). International Journal of Industrial Engineering Research and Development, 2(1), 59-68.

Khan, M. S. (2016). Impact of Promotional Mix Elements on Tourist's Satisfaction : A Case Study of Mussoorie. International Journal of Research in Commerce and Management, $7(4)$.

Koththagoda, K. (2017). The Impact of Perceived Brand Equity on Customer Satisfaction: with Special Reference to Emerging Tourism Destinations. South Asian Journal of Marketing and Management Research, 7(2). https://doi.org/10.5958/2249877X.2017.00005.4

Kotler, P., \& Keller, K. L. (2016). Marketing Management, 15th Edition (P. Kotler \& K. L. Keller (eds.); 15th ed.). Pearson. https://doi.org/10.4236/ait.2017.73004 2,059

Malik, E. M., Naeem, B., \& Nasir, A. M. (2011). Impact of Service Quality on Brand Image : Empirical Evidence from Hotel Industry. Interdisciplinary Journal of Contemporary Research in Business, 3(8), 630-636.

Noori, A., \& Nisa, S. (2019). An investigation on how brand image influences tourist destination and customer satisfaction: A case of the tourism sector. International Journal of Scientific and Technology Research, 8(11), 3553-3559.

Puri, G., \& Singh, K. (2018). The Role of Service
Quality and Customer Satisfaction in Tourism Industry : A Review of Servqual Model. International Journal of Research and Analytical Reviews, 5(4), 745-751.

Rahayu, S. (2015). The Effect of Promotion, Service Quality, Brand Image on the Satisfaction of the Tourists Visiting the City Palembang and the Implication on Their Loyalty to the Visited Resorts. Journal of Business and Economics, 6(4), 770-780. https://doi.org/10.15341/jbe(21557950)/04.06.2015/012

Review, M. Q., Osman, Z., \& Sentosa, I. (2013). Influence of Customer Satisfaction on Service Quality and Trust. 4(2), 12-25.

Salleh, M., Omar, K., \& Yaakop, A. Y. (2013). Tourist Satisfaction in Malaysia. International Journal of Business and Social Science, 4(5), 221-226. https://doi.org/10.30845/ijbss

Singh, R., \& Mehraj, N. (2018). Destination brand experience and its relationship with tourists satisfaction and intention to recommend: A conceptual model. African Journal of Hospitality, Tourism and Leisure, 7(1), 1-13.

Stefan, A. N. (2013). Business Strategies in Tourism. Ecoforum, 2(1), 1. 